\title{
COMPARING THE EFFECT OF CONVENTIONAL PHYSICAL THERAPY APPLICATIONS AND KINESIOLOGICAL TAPING ON PAIN INTENSITY AND QUALITY OF LIFE IN CHRONIC BACK AND LEG PAIN PATIENTS
}

\author{
Burcu ÖZÜBERK', Nihal BÜKER' \\ 'School of Physical Therapy and Rehabilitation, Pamukkale University, Denizli, TURKEY.
}

\section{ABSTRACT}

Objectives: The aims of this study are to compare effects of conventional physical therapy and kinesiology taping methods on the patients with chronic low back and leg pain and to control in terms of pain intensity and quality of life.

Materials and Methods: A total of 48 participants were randomly divided into two groups; kinesiologic taping group and control group. The participants in both groups received a conventional physical therapy program. Kinesiologic taping group received four sessions a conventional physical therapy plus kinesiology tape on the piriformis muscle and sciatic nerve. Pain intensity (Visual Analog Scale), disability (Oswestry Disability Index), quality of life (Nottingham Health Profile), anxiety symptoms (Beck anxiety Inventory) were measured at baseline and after the treatment program.

Results: According to the groups comparison, there is no statistical significance $(p>0.05)$ in pain, physical competence, anxiety level and quality of life.

Conclusion: In the results of this study, kinesiology taping method has not changed pain, quality of life, anxiety and disability level for participants with chronic low back and leg pain. Also application of kinesiotaping did not cause to allergic reactions in those who participated.

Key Words: Low back pain; Kinesiologic Taping; Physiotherapy; Quality of Life.

\section{INTRODUCTION}

Low back pain is non-specific pathological condition usually that cannot be attributed to a known specific pathology and that is accompanied by leg pain (sciatica) on some patients characterized by pain between rib lower line and inferior gluteal line [1,2] and that prevents or delays the treatment of such patients[3]. It is important to define the underlying pathology in spreading leg pain to provide the effective and proper treatment. It is possible to use tests such as straight leg raise test (SLRT) [4] and passive stretching of muscle (Freiberg and FADIR test) $[5,6]$ or active contraction of muscle (Pace test) [7] against resistance in order to differentiate the sciatic neuropathy condition (piriformis syndrome) that occur due to the pressure of piriformis muscle to the sciatic nerve.

Kinesio taping treatment is a technique that is growing widely popular in the recent years and that allows solving of the problems with a different perspective by contributing to the circulatory

*Corresponding author:

Email: brc fzt@hotmail.com

http://dx.doi.org/10.20530/IJTA $33 \quad$ 139-144

ISSN 2320-138X @ 2016 system besides many musculoskeletal problems with various techniques used [8]. As per the acting mechanism of the kinesio taping, it helps circulation by lifting the skin upwards in the area where taping is applied and increasing the flow rate of blood and lymph. Its role in relief of pain is tried to be explained by different mechanisms such as reduction of edema and inflammation on one hand, and activation of gate-control and descending inhibitor mechanisms with sensory stimulations, analgesic effect by regulation of superficial and deep fascia functions etc. $[9,10]$.

We have aimed to represent a different treatment approach in the chronic low back pain treatment and determine the effects of kinesio taping on the pain and the quality of life in our study.

\section{MATERIALS AND METHOD}

A total of 437 patients who have appealed to the Physical Therapy and Rehabilitation Clinic and who have low back and leg pain more than 3 months were examined. 248 of these patients were diagnosed with lumbar disc herniation (LDH), 107 were diagnosed with LDH+myelopathy, 1 with sciataalgia, and 81 with lumbago+sciatica. Of these 437 patients, ones with pains caused by infectious, inflammatory, tumoral, metabolic reasons that may cause low back pain, ones with that reflect 
from fractures, abdominal or pelvic organs, and ones who had spinal operations and ones with instability problems such as spondylolisthesis, spondylodesis etc. were not included in the study. Written consent of the patients who were included in the study was taken. 59 patients who are included in the study were divided into two groups using the random numbers method, and these groups were conventional physical treatment group (Group I, $\mathrm{n}=31$ ) and conventional physical treatment + kinesio taping group (Group II, $n=28$ ). 11 patients (4 from kinesio taping group, and 7 patients from conventional physical treatment group) were excluded from the study as they did not attend the treatment regularly.

Patients in the conventional physical treatment group, with an average of $52.16 \pm 16.28$ years, were treated with hotpack (HP) at $60^{\circ} \mathrm{C}$ for 20 minutes, therapeutic ultrasound (US) of 1.5 watt $\backslash \mathrm{cm}^{2}$, for a total of 4 minutes ( 2 minutes + 2 minutes) by paravertebral application, conventional TENS for 20 minutes by paravertebral application. A total of 10 therapy sessions, 1 session per day, at the same time of the day, for 5 times a week, were applied to the patients in the conventional physical treatment group. Patients in the conventional physical treatment and kinesio taping group, with an average of $45.54 \pm 12.49$ years, were treated with kinesio taping for a total of 4 times, as 2 times per week through the treatment period, with a strain of $10-15 \%$ to the piriformis muscle to the sciatic nerve trace in addition to the treatment in conventional physical treatment group. Evaluation of the patients, both pre and post treatment were performed by a researcher who was blind to study.

Meta-datas of the facts were recorded in a form prepared in advance. Straight Leg Raise test (SLRT) and Flexion/ Adduction/Internal Rotation Test (FADIR) test results were recorded in order to determine the leg pain.

A standardized Visual Analog Scale (VAS) was applied to determine the pain level. Patients were asked to indicate the pain they feel with an " $X$ " on a $10 \mathrm{~cm}$ scale [11].

Oswestry Disability Index (ODI) questionnaire was used to determine the disability level. Questionnaire consists of 10 subgroups that questions intensity of pain, ability to care for oneself, ability to lift-handle, ability to walk, ability to sit, ability to stand, sleep quality, sexual function, ability to travel and social life. Total score of the questionnaire varies from 0 to 50 , and disability level increases as the total score increases [12].

The anxiety level was determined with Beck Anxiety Scale (BAS). This scale consists of 21 articles and anxiety level for each symptom is evaluated by 4 scales from 0 (none) to 3 (severe) [13].

Quality of life was evaluated using the Nottingham Health Profile (NHP). This consists of 38 yes-no questions in six categories comprising of energy, pain, physical mobility, sleep, emotional reactions and social isolation. Positive answers to specific fields are used in evaluating the intensity in this questionnaire which queries about the complaints at that time, or it is possible to provide the total of six categories as a profile [14].

\section{Statistical Analysis}

Data obtained in the study were calculated by a

Table 1 : Definitive Information of the Patients

\begin{tabular}{|c|c|c|c|c|}
\hline \multirow[t]{2}{*}{ Variables } & \multicolumn{2}{|c|}{ Physical Treatment Group } & \multicolumn{2}{|c|}{ Kinesio Taping Group } \\
\hline & & $X \pm S D$ & & $X \pm S D$ \\
\hline Age (years) & & $52.16 \pm 16.28$ & & $45.54 \pm 12.49$ \\
\hline Height $(\mathrm{cm})$ & & $1.63 \pm 0,089$ & & $1.64 \pm 0,066$ \\
\hline Weight (kg) & & $78.83 \pm 15.27$ & & $73.83 \pm 12.20$ \\
\hline $\mathrm{BMI}\left(\mathrm{kg} / \mathrm{cm}^{2}\right)$ & & $29.55 \pm 6.08$ & & $27.53 \pm 5.11$ \\
\hline \multirow[t]{2}{*}{ Education (years) } & & $6.93 \pm 3.82$ & & $8.04 \pm 3.96$ \\
\hline & $\mathbf{N}$ & $\%$ & $\mathbf{N}$ & $\%$ \\
\hline \multicolumn{5}{|l|}{ Gender } \\
\hline Female & 17 & $70.8 \%$ & 19 & $79.2 \%$ \\
\hline Male & 7 & $29.2 \%$ & 5 & $20.8 \%$ \\
\hline \multicolumn{5}{|l|}{ Employment } \\
\hline Employed & 3 & $12.5 \%$ & 5 & $20.8 \%$ \\
\hline Unemployed & 19 & $79.2 \%$ & 18 & $75.0 \%$ \\
\hline Retired & 2 & $8.3 \%$ & 1 & $4.2 \%$ \\
\hline
\end{tabular}

BMI: Body Mass Index; *Independent sample t test; ${ }^{* *}$ Chi-square test 
computer software pack called SPSS for Windows (version 16.0). Continuous and categorical data are reported as mean \pm standard deviation and number (percentages), respectively Paired Samples $t$ Test was used for comparisons inside the groups and Independent Sample $t$ Test was used for comparisons between the groups. $p<0.05$ level was considered as statistically significant.

\section{RESULT}

Average age of the patients in the conventional physical treatment group $(n=24)$ was $52.16 \pm 16.28$ years, and the average age of the patients in the conventional physical treatment plus kinesio taping group was $45.54 \pm 12.49$ years. Other definitive information on the patients is given in Table I.

Straight Leg Raise test (SLRT) resulted as positive in $81.2 \%$ of the patients, and negative in $18.8 \%$ of the patients And,Flexion/ Adduction/Internal Rotation Test resulted as positive in $83.3 \%$ of the patients, and negative in $16.7 \%$ of the patients (Table 1 ).

No statistical significance was observed when the pain levels, anxiety and disability conditions of the patients in the conventional physical treatment group pre and post therapy ( $p>0.05)$.

While no statistically significant difference was observed when the pain levels, pre and post therapy, of the patients in the kinesio taping group were examined in terms of resting and activity pains, a statistically significant difference was observed in the sleep pain post treatment $(p<0.05)$. While no statistically significant difference was observed pre and post therapy in the anxiety condition, a statistically significant difference was observed in the disability conditions $(p<0.05)$ (Table 2).

A statistically significant difference was observed when the quality of life of the patients in both groups were compared pre and post therapy $(p<0.05)$. Especially, it was observed that the general quality of life under the heading of pain was statistically different for the group applied with kinesiotaping $(p<0.05)$ (Table3).

\section{DISCUSSION}

In this random controlled, planned as single blind, conventional physical treatment was applied to the control group, and kinesio taping was applied in addition to the conventional physical treatment to the research group in order to determine the effectiveness of kinesio taping application. In our study, where there is no statistically significant difference in terms of demographical characteristics between the groups, we have observed reduction in sleep pain, improvement in disability level, improvement in quality of life and finally improvement in the pain level, as a sub-group of the quality of life, for the second group while we have observed an improvement in quality of life only for the first group in the comparison between groups pre and post the treatment. However, no statistically significant difference was observed between the groups pre and post the treatment in the comparisons between the groups.

Trapping of sciatic by the piriformis muscle is one of the reasons that increase the low back pain.

Table 2 : Comparison of VAS, ODI and BAS values between groups through the treatment period of the groups

\begin{tabular}{|c|c|c|c|c|}
\hline \multirow[t]{2}{*}{ Variables } & Physical Treatment & Kinesio Taping & $\mathbf{t}$ & $\mathbf{p}$ \\
\hline & $X \pm S D$ & $X \pm S D$ & & \\
\hline \multicolumn{5}{|l|}{ VAS activity } \\
\hline Pre-op & $5.41 \pm 2.35$ & $4.50+2.62$ & 1.274 & 0.209 \\
\hline Post-op & $4.58 \pm 2.56$ & $4.12+2.64$ & & \\
\hline \multicolumn{5}{|l|}{ VAS rest } \\
\hline Pre-op & $3.70 \pm 2.59$ & $4.04+2.61$ & -0.443 & 0.660 \\
\hline Post-op & $3.41 \pm 2.48$ & $3.12+2.02$ & & \\
\hline \multicolumn{5}{|l|}{ VAS sleep } \\
\hline Pre-op & $4.37 \pm 2.91$ & $5.04+2.59$ & -0.837 & 0.407 \\
\hline Post-op & $4.62 \pm 2.74$ & $3.62+2.97$ & & \\
\hline \multicolumn{5}{|l|}{ BAS } \\
\hline Pre-op & $19.79 \pm 13.33$ & $19.37+9.09$ & 0.126 & 0.900 \\
\hline Post-op & $17.95 \pm 14.18$ & $17.58+11.61$ & & \\
\hline \multicolumn{5}{|l|}{ ODI } \\
\hline Pre-op & $27.95+8.47$ & $28.75+8.43$ & -0.324 & 0.747 \\
\hline Post-op & $25.70+11.94$ & $22.95+9.69$ & & \\
\hline
\end{tabular}

VAS: Visuel Analog Scale; BAS: Beck Anxiety Scale; ODI: Oswestry Disability Index; ${ }^{*}$ Independent sample t test 
Table 3 : Comparison of NHP and its sub-values between groups through the treatment period of the groups

\begin{tabular}{|c|c|c|c|c|}
\hline Variables & $\begin{array}{c}\text { Physical Treatment } \\
\text { Group } \\
\text { X } \pm S D\end{array}$ & $\begin{array}{c}\text { Kinesio Taping Group } \\
\text { X } \pm \text { SD }\end{array}$ & $\mathbf{t}$ & $\mathbf{p}$ \\
\hline \multicolumn{5}{|l|}{ NHP PA } \\
\hline Pre-op & $42.92+20.36$ & $37.04+14.77$ & 1.145 & 0.258 \\
\hline Post-op & $39.72+21.52$ & $39.21+21.52$ & & \\
\hline \multicolumn{5}{|l|}{ NHP SI } \\
\hline Pre-op & $23.69 \pm 29.75$ & $23.12 \pm 24.43$ & & \\
\hline Post-op & $18.07 \pm 23.95$ & $15.30 \pm 24.03$ & 0.072 & 0.943 \\
\hline \multicolumn{5}{|l|}{ NHP EL } \\
\hline Pre-op & $69.33+35.64$ & $73.30+37.05$ & & \\
\hline Post-op & $65.70+41.28$ & $64.36+34.52$ & -0.378 & 0.707 \\
\hline \multicolumn{5}{|l|}{ NHP ER } \\
\hline Pre-op & $50.99+29.52$ & $44.07+25.55$ & 0.869 & 0.389 \\
\hline Post-op & $44.03+33.67$ & $34.76+25.70$ & & \\
\hline \multicolumn{5}{|l|}{ NHP P } \\
\hline Pre-op & $70.83+24.99$ & $72.75+24.82$ & -0.268 & 0.790 \\
\hline Post-op & $61.32+31.66$ & $60.58+28.15$ & & \\
\hline \multicolumn{5}{|l|}{ NHP S } \\
\hline Pre-op & $49.01+34.20$ & $44.69+31.38$ & 0.455 & 0.651 \\
\hline Post-op & $46.00+32.66$ & $37.64+32.76$ & & \\
\hline \multicolumn{5}{|l|}{ NHP total } \\
\hline Pre-op & $3.06 \pm 135.55$ & $2.95 \pm 94.11$ & 0.350 & 0.728 \\
\hline Post-op & $2.74 \pm 142.17$ & $2.51 \pm 113.61$ & & \\
\hline
\end{tabular}

NSP PA: Physical Abilities; NSP SI: Social İsolation; NSP EL: Energy Level; NSP ER: Emosyonel Reaction; NSP P:Pain; NSP S: Sleep; NSP total: NSP total score; *Independent sample t test

This is a diagnosis that is easily missed, but that reduces low back pain significantly when it is considered in the treatment. There will be painful points through the sciatic nerve line besides the pains in the low back and legs in case of a low back pain. As a result of trapping the sciatic nerve by the piriformis muscle, hip and leg pain, and dysesthesia that spreads behind the thigh and rarely to the leg and foot [15]. In the studies performed before, several kinesio taping applications by different techniques applied to the low back area on the patients with low back pain and positive effects of these applications were shown [16-20]. In our study, we have performed the application throughout sciatic nerve trace and on the piriformis muscle in order to relax the piriformis muscle and inhibit the pained points that occur through sciatic nerve trace instead of applying kinesio taping directly on the low back area.

A decrease in the pain levels felt pre treatment and post treatment for both groups was observed, but this decrease was more significant in patients who were applied kinesio taping. A statistically significant difference was observed especially in the sleep pain for the kinesio taping group $(p<0.05)$. Results of our study suggests that kinesio taping applied in addition to conventional physical treatment method has positive effects on the pain relief of the patients.

The role of kinesio taping in relief of pain is provided by the reduction of edema and inflammation on one hand, and analgesic effect by regulation of superficial and deep fascia functions on the other hand besides activation of gatecontrol and descending inhibitor mechanisms with sensory stimulations [21]. As it can be seen, kinesio taping allows reduction of pain in the patients by activating the lymph and blood circulation, too, besides the gate-control system. This explains the reason of the fact that the reduction in pain in the kinesio taping group is higher than the conventional physical treatment group.

A statistical significance was observed in the comparison of disability condition pre and post treatment on the group where kinesio taping is applied only $(p>0.05)$. A positive relation between the pain condition and disability condition of the patients in the conventional physical treatment group may also be observed. Disability condition decreases as the level of pain decreases. However, when the results of both groups post therapy, for 
the comparison made, were examined, it was observed that while kinesio taping application provided a difference, even as minimal, in the favor of the second group in disability condition, it did not provide a difference in the statistically significant sense $(p>0.05)$. It has been stated that kinesio taping may be used in order to support low back muscles, to accelerate the recovery of tissues, to increase body flexion and to decrease disability condition in the literature [20,22].

No statistical significance was observed for both groups in the evaluation of anxiety level pre and post treatment in our study $(p>0.05)$. Quality of life is reduced for patients with chronic low back pain as their activities are restricted. This triggers depressive mood in the patient and causes establishment of sadness and pessimism and causes the person to be demotivated quite fairly [23]. Thus, we interpret that the fact that anxiety level does not provide a significant result as there is no difference in the pain levels. In many studies, it was presented that physical restriction is related with psychological dysfunction rather than the pain [24] and factors such as general condition of health, work-related problems and psychological factors increased the incidence, recurrence of the pain and increased its tendency to become chronic [25].

Exercise therapy is the most applied conservative approach in the clinic and it is the method recommended for acute and chronic low back pain in the studies [26-28], but the as the persons with back pain are demotivated, they do not only lose the interest for making exercises, they even lose the will to continue the treatment. In our study, we have obtained control of pain as a result of the regulation of circulation by increasing the clearance between superficial fascia and deep fascia through the skin by using kinesio taping, and also obtained relaxation by taping the sciatic nerve with the inhibition method. Here, the aim was to get through the painful period with taping in the short term by embarking the burden of exercise to the kinesio taping without forcing patients to exercise in their painful periods. Also, we wished to observe the effect of the kinesio taping as isolated in order to offer a different perspective for treatment as there are many studies examining the effect of kinesio taping together with the exercise. Another reason that we did not include the exercise in our study is that the period of treatment was so short as 10 sessions. When we review the literature, the effectiveness of exercise is usually evaluated by observing long term results [29-31].
We have thought this study, in which we have examined the effectiveness of kinesio taping application in patients with chronic low back pain, as a means for providing a different approach for the clinical researchers both by showing the shortterm effects of kinesio taping on important criteria such as pain and life quality and by offering a different perspective in the treatment of these patients.

\section{CONFLICT OF INTEREST AND FINANCIAL STATEMENT}

Author(s) don't have any conflict of interest in any case relevant to the article.

No financial support was acquired pertaining to the study.

\section{REFERENCES}

[1] Manek JN, MacGregor AJ. Epidemiology of back disorders: prevalence, risk factors and prognosis. Curr Opin Rheumatol. 2005; 17:134-140.

[2] Waddel G. The back pain revolution, London, Churchill Livingstone; 2004.

[3] Dunn KM, Croft PR. Epidemiology and natural history of low back pain. Eura Medicophys. 2004; 40: 9-13.

[4] Dixon JK, Keating JL. Variability in Straight Leg Raise Measurements. Physiotherapy. 2000 Jul;86(7):361$70 . \quad$ Available from: http://dx.doi.org/10.1016/s0031-9406(05)60630-x.

[5] Freiberg $A H$, Vinke TH. Sciatica and the sacroliac joint. J Bone Joint Surg Am. 1934;16: 126-136.

[6] BENSON ER, SCHUTZER SF. Posttraumatic Piriformis Syndrome. The Journal of Bone and Joint SurgeryAmerican Volume. 1999 Jul;81(7):941-9. Available from: http://dx.doi.org/10.2106/00004623199907000-00006.

[7] Pace JB, Nagle D. Piriform syndrome. West J Med 1976; (124): 435-439.

[8] Williams S, Whatman C, Hume PA, Sheerin K. Kinesio Taping in Treatment and Prevention of Sports Injuries. Sports Medicine. 2012 Feb;42(2):153-64. Available from: http://dx.doi.org/10.2165/11594960-00000000000000.

[9] Kalichman L, Vered E, Volchek L. Relieving Symptoms of Meralgia Paresthetica Using Kinesio Taping: A Pilot Study. Archives of Physical Medicine and Rehabilitation. 2010 Jul;91(7):1137-9. Available from:

http://dx.doi.org/10.1016/j.apmr.2010.03.013.

[10] Kase K, Wallis J, Kase T. Clinical therapeutic applications of the Kinesio ${ }^{\circledR}$ Taping metho. Tokyo, Japan: Kinesio Taping Association, Ken Ikai Co. Ltd, 2003. 
[11] Melzack R. The short-form McGill pain questionnaire. Pain. 1987 Aug;30(2):191-7. Available from: http://dx.doi.org/10.1016/03043959(87)91074-8.

[12] Yakut E, Düger T, Öksüz Ç, Yörükan S, Üreten K, Turan D, et al. Validation of the Turkish Version of the Oswestry Disability Index for Patients With Low Back Pain. Spine. 2004 Mar;29(5):581-5. Available from:

http://dx.doi.org/10.1097/01.brs.0000113869.1320 9.03 .

[13] Kabacoff RI, Segal DL, Hersen M, Van Hasselt VB. Psychometric properties and diagnostic utility of the Beck Anxiety Inventory and the state-trait anxiety inventory with older adult psychiatric outpatients. Journal of Anxiety Disorders. 1997 Jan;11(1):33-47. Available from: http://dx.doi.org/10.1016/s0887-6185(96)00033-3.

[14] Ku cu kdeveci AA, Yavuzer G, Elhan AH, Sonel B, Tennant A. Adaptation of the Functional Independence Measure for use in Turkey. Clinical Rehabilitation. 2001 Jun 1;15(3):311-9. Available from:

http://dx.doi.org/10.1191/026921501676877265.

[15] Jeong HS, Lee GY, Lee EG, et al. Long-term assessment of clinical outcomes of ultrasoundquided steroid injections in patients with piriformis syndrome. Ultrasonography. 23 January 2015; doi:10.14366.

[16] Paoloni M, Bernetti A, Fratocchi G, et al. Kinesio Taping applied to lumbar muscles influences clinical and electromyographic characteristics in chronic low back pain patients. Eur J Phys Rehabil Med. June 2011; 47(2):237-44.

[17] AlBahel F, Hafez AR, Zakaria AR, et al. Kinesio Taping for the Treatment of Mechanical Low Back Pain, World Applied Sciences Journal 2013; 22 (1): 78-84, DOI: 10.5829/idosi.wasj.2013.22.01.72182.

[18] Keyvan Y, Seyed SS, Jandark E. A study on the effect of pilates exercise, kinesio tape and combined method on pain and functional disability in nonspecific chronic low back pain, Scholars Research Library, Annals of Biological Research, 2013;4 (12):143-149.

[19] Hwang-Bo G, Lee JH. Effects of kinesio taping in a physical therapist with acute low back pain due to patient handling: A case report in International Journal of Occupational Medicine and Environmental Health, 2011;(24), 3: 320-323.

[20] Yoshida A, Kahanov L. The Effect of Kinesio Taping on Lower Trunk Range of Motions. Research in Sports Medicine. 2007 Apr;15(2):103-12. Available from:

http://dx.doi.org/10.1080/15438620701405206.
[21] Kase K, Wallis J, Kase T. Clinical therapeutic application of the kinesio taping method. Tokyo, Japan: Ken Ikai Co Ltd. 2003.

[22] Castro-Sánchez AM, Lara-Palomo IC, MataránPeñarrocha GA, Fernández-Sánchez $M$, SánchezLabraca N, Arroyo-Morales M. Kinesio Taping reduces disability and pain slightly in chronic nonspecific low back pain: a randomised trial. Journal of Physiotherapy. 2012 Jun;58(2):89-95. Available from: http://dx.doi.org/10.1016/s18369553(12)70088-7.

[23] Özcan ME, Yurtsızoğlu Ö, Balki S, et al. Bel ağrısı olan hastalarda hot-pack, TENS, ultrasound ve egzersizin HAM-D skorlarına etkisi. Anadolu Psikiyatri Dergisi 2000; 1: 26-31.

[24] Liddle SD, Baxter DG, Gracey JH. Exercise and chronic low back pain: what works? Pain. 2004 Jan;107(1):176-90. Available from: http://dx.doi.org/10.1016/j.pain.2003.10.017.

[25] Elders LAM, Burdorf A. Prevalence, Incidence, and Recurrence of Low Back Pain in Scaffolders During a 3-Year Follow-up Study. Spine. 2004 Mar;29(6):E101-E106. Available from: http://dx.doi.org/10.1097/01.brs.0000115125.6033 1.72.

[26] Airaksinen O, Brox JI, Cedraschi C, Hildebrandt J, Klaber-Moffett J, Kovacs F, et al. Chapter 4 European guidelines for the management of chronic nonspecific low back pain. European Spine Journal. 2006 Mar;15(S2):s192-s300. Available from: http://dx.doi.org/10.1007/s00586-006-1072-1

[27] Scharrer M, Ebenbichler G, Pieber K, et. al. A systematic review on the effectiveness of medical training therapy for subacute and chronic low back pain. Eur J Phys Rehabil Med. 2012; 48:361-370.

[28] Chou R, Loeser JD, Owens DK, Rosenquist RW, Atlas SJ, Baisden J, et al. Interventional Therapies, Surgery, and Interdisciplinary Rehabilitation for Low Back Pain. Spine. 2009 May;34(10):1066-77. Available from: http://dx.doi.org/10.1097/brs.0b013e3181a1390d.

[29] Maul I, Läubli T, Oliveri M, Krueger H. Long-term effects of supervised physical training in secondary prevention of low back pain. European Spine Journal. 2005 Feb 16;14(6):599-611. Available from: http://dx.doi.org/10.1007/s00586-004-08733.

[30] Van Tulder M, Malmivaara A, Esmail R, Koes B. Exercise Therapy for Low Back Pain. Spine. 2000 Nov;25(21):2784-96. Available from: http://dx.doi.org/10.1097/00007632-20001101000011.

[31] Quittan M. Management of back pain. Disability and Rehabilitation. 2002 Jan;24(8):423-34. Available from: http://dx.doi.org/10.1080/09638280110108850. 